\title{
Avaliação do desempenho de aditivos comerciais superplastificantes a base de policarboxilato nas propriedades mecânicas e microestruturais de pastas de cimento Portland
}

\author{
Performance evaluation of commercial \\ superplasticizing additives based on polycarboxylate \\ on the mechanical and microstructural properties \\ of Portland cement pastes
}

\begin{abstract}
André Valmir Saugo Ribero ${ }^{1}$, Laura Silvestro ${ }^{1}$, Ana Julia Zunta Carniel ${ }^{1}$, Matheus Agustini ${ }^{1}$, Priscila Warsch ${ }^{1}$, Wellington Longuini Repette ${ }^{1}$, Philippe Jean Paul Gleize ${ }^{1}$
\end{abstract}

\footnotetext{
${ }^{1}$ Programa de Pós-Graduação em Engenharia Civil, Universidade Federal de Santa Catarina, Florianópolis, Santa Catarina, Brasil.

e-mail: andrecivilutfpr@gmail.com, laurasilvestro@gmail.com, anajuliacarniel@hotmail.com matheus-agustini@hotmail.com, priscilawarsch@gmail.com,wellington.repette@ufsc.br,p.gleize@ufsc.br
}

\section{RESUMO}

O desempenho de aditivos plastificantes está diretamente relacionado com as características da molécula empregada na sua fabricação e, nesse caso, varia de acordo com a sua procedência. Neste contexto, o objetivo deste estudo é avaliar o desempenho de quatro aditivos comerciais à base de policarboxilato em pastas de cimento Portland com baixas relações água/cimento. Os aditivos foram caracterizados por meio de ensaios de teor de sólidos e Espectroscopia de Infravermelho com Transformada de Fourier. Já o desempenho dos aditivos nas pastas foi avaliado pelos ensaios de mini-abatimento, teor de ar incorporado, resistência à compressão aos 28 dias e termogravimetria. Para ambas as relações a/c avaliadas, os quatro aditivos apresentaram espalhamentos diferentes para um mesmo teor de sólidos utilizado. Também se constatou que diferentes tipos de aditivos ocasionaram alterações distintas nos períodos de indução, bem como, diferentes incorporações de ar, que acarretaram diferentes resistências à compressão das pastas, de maneira que a maior resistência à compressão pode ser atribuída ao menor teor de ar incorporado. Estes resultados podem ser explicados porque o desempenho do aditivo está associado ao tamanho da sua molécula, cadeias laterais, peso molecular e a adsorção da molécula nos compostos químicos do cimento. Verificando que mesmas bases químicas de aditivos (policarboxilatos) resultam em diferentes comportamentos de misturas cimentícias, ressalta-se que é de suma importância o teste prévio de compatibilidade entre o cimento Portland e o aditivo químico que será utilizado na produção da matriz cimentícia.

Palavras-chave: cimento Portland, superplastificante, policarboxilato, desempenho

\section{ABSTRACT}

The performance of dispersing admixtures is directly related to the characteristics of the utilized molecule and it can vary according from the original. In this context, the objective of this study is to evaluate the performance of four commercial polycarboxylate-based in Portland cement pastes with low w/c ratio. The admixtures were characterized through tests of solids content and Fourier Transform Infrared Spectroscopy. The performance of the admixtures in the pastes was evaluated by the mini-slump test, as well as by the air void content, compressive strength at 28 days and thermogravimetry. For both a / $\mathrm{c}$ ratios evaluated, the four additives showed different spreadings for the same solids content used. It was also found that different types of additives caused different changes in the induction periods, as well as different air incorporations, which 
resulted in different compressive strengths of the pastes, so that the greatest compressive strength can be attributed to the lowest content of incorporated air. These results can be explained because the performance of the additive is associated with the size of its molecule, side chains, molecular weight and the adsorption of the molecule in the chemical compounds of cement. Noting that the same chemical bases of additives (polycarboxylates) result in different behaviors of cement mixtures, it is emphasized that the prior compatibility test between Portland cement and the chemical additive that will be used in the production of the cement matrix is of paramount importance.

Keywords: Portland cement, superplasticizer, polycarboxylate, performance

\section{INTRODUÇÃO}

Diante da demanda por argamassas e concretos com baixas relações água/cimento e elevadas resistências à compressão, a utilização de aditivos plastificantes de terceira geração tem crescido na indústria da construção civil. Atualmente, os aditivos plastificantes são, comumente, os mais utilizados, uma vez que esses modificam a reologia de misturas cimentícias com baixa relação água/cimento, para que assim, possam ser mais facilmente empregadas ao uso [1]. Esses aditivos, também chamados de aditivos redutores de água, além de serem utilizados para melhorar a trabalhabilidade das misturas, permitem aumentar a sua resistência à compressão e o módulo de elasticidade no estado endurecido, quando utilizados para redução da quantidade de água em um determinado teor de cimento constante [2].

Os aditivos à base de poliacrilatos são chamados de superplastificantes de terceira geração, tendo como mecanismo de ação a repulsão estérica. Esse tipo de aditivo geralmente promove uma melhor dispersão das partículas pela redução na tensão superficial da água de amassamento, que ocorre pela presença de grupos funcionais, bem como por uma diminuição no atrito pelo alinhamento de polímeros lineares ao longo da direção do fluxo de misturas cimentícias e propriedades de lubrificação que são produzidas por polímeros de baixa massa molecular. Assim, a melhor dispersão das partículas de cimento promove uma melhor hidratação da mistura [3]. Segundo MEHTA e MONTEIRO [4], ocorre uma maior velocidade de hidratação das partículas de cimento em uma mistura com superplastificante, quando o sistema encontra-se com boa dispersão, proporcionando maiores resistências iniciais em um, três e sete dias, quando comparado com uma mistura que não contenha $o$ aditivo.

Deve-se tomar cuidado com a utilização em demasia desse tipo de aditivo, já que pode ser promovido um retardo na reação de hidratação nas primeiras horas, decorrente da formação de um filme hidrofóbico na superfície dos reagentes que impede o processo de hidratação durante o período inicial [5]. Esse atraso no processo de hidratação foi verificado no trabalho de VALENTINI, DALCONI e ARTIOLI [6] quando estudado o papel do aditivo superplastificante de policarboxilato-éter na cinética de hidratação do cimento e no desenvolvimento microestrutural. Seus resultados inferem que a nucleação e o crescimento de C-S-H exercem um papel fundamental no controle da cinética de hidratação geral e as moléculas do aditivo induzem a um atraso, agindo no modo e na taxa de precipitação de C-S-H. Os autores comentam que houve uma mudança de nucleação heterogênea para homogênea, quando se fez a utilização do aditivo. Segundo RIXOM e MAILVAGANAM [7], embora uma superdosagem do aditivo possa causar um retardo na reação de hidratação das partículas de cimento em idades iniciais, os autores afirmam que, aos 28 dias os produtos de hidratação gerados são os mesmos do que um sistema que não foi utilizado o superplastificante.

Nessa conjuntura, problemas relacionados à dosagem excessiva de aditivo podem ser solucionados pela determinação do seu teor de saturação, sendo esse ensaio essencial para otimização do uso de aditivos em misturas cimentícias [8]. Além disso, é de fundamental importância verificar a compatibilidade entre o aditivo e o cimento a ser empregado. Isto porque, de acordo com GOLASZEWSKI [9], as características do ci-

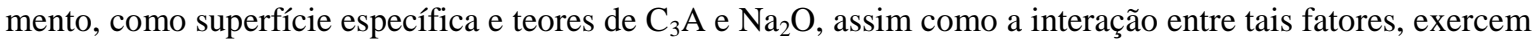
elevada influência no comportamento reológico das misturas de cimento e no desempenho dos policarboxilatos. De maneira geral, o autor constatou que a performance dos superplastificantes avaliados diminuiu com o aumento dos teores de $\mathrm{C}_{3} \mathrm{~A}$ e $\mathrm{Na}_{2} \mathrm{O}$ e da superfície específica do cimento utilizado.

Aditivos de mesma base molecular podem apresentar desempenhos diferentes devido a fatores intrínsecos presentes em cada produto. JANOWSKA-RENKAS [1] cita que a eficiência e o desempenho de superplastificantes comerciais aumentam com o peso molecular do polímero, assim como com a sua fração de massa na amostra. $\mathrm{O}$ autor ainda afirma que os principais fatores intrínsecos que influenciam no desempenho de aditivos de mesmo tipo de molécula estão ligados às suas estruturas químicas e, particularmente, ao comprimento e arranjo das cadeias principal e lateral, teor de sólidos presentes e a compatibilidade química com o cimento utilizado.

Nesse contexto, LANGE, HIRATA e PLANK [10] mencionam que a capacidade de dispersão de um 
polímero está diretamente ligada à quantidade e à espessura da camada adsorvida na superfície das partículas de cimento. RAN et al. [11] constataram que a quantidade de aditivo policarboxilato adsorvida na superfície do cimento é função do teor de carboxilato $\left(\mathrm{COO}^{-}\right)$e do comprimento das cadeiras laterais, como já indicado por JANOWSKA-RENKAS [1]. De acordo com ZHANG et al. [12], o efeito dos polímeros a base de policarboxilato, na microestrutura e nas propriedades das pastas de cimento Portland no estado fresco, é determinado pelas suas características de carga, sendo que a capacidade de adsorção dos grupos funcionais pode ser classificada na seguinte ordem: $-\mathrm{COO}^{-}>-\mathrm{SO}_{3}{ }^{-}>\equiv \mathrm{N}^{+}-$. De acordo com tais autores, polímeros com mais grupos carboxilatos exibem melhor capacidade de dispersão de partículas de cimento e um efeito mais pronunciado no aumento do período de indução.

Isto posto, diversos trabalhos encontrados na literatura que avaliaram a influência de diferentes tipos de aditivos superplastificantes à base de policarboxilato nas propriedades mecânicas e microestruturais de matrizes de cimento Portland, de maneira geral, sintetizaram as moléculas do aditivo em laboratório [10, 13, 14]. Contudo, como essa conduta se distância da aplicação prática, este trabalho teve como objetivo avaliar a influência de quatro tipos de aditivos superplastificantes comercialmente disponíveis nas propriedades de pastas de cimento Portland. Entretanto, destaca-se a carência de informações fornecida pelos fabricantes dos produtos no que tange à caracterização química destes aditivos e a limitação de ensaios disponíveis para a realização desta caracterização. Diante do exposto, a pesquisa em questão tem como objetivo chamar a atenção para a importância da realização de testes com aditivos de mesma molécula que tenham diferentes procedências, isso porque, aditivos com base molecular equivalente não necessariamente apresentam o mesmo desempenho em uma mistura cimentícia, visto que o seu desempenho não está atrelado somente ao tipo de molécula presente no produto.

Diante desse contexto, o presente trabalho tem como objetivo avaliar o desempenho, em misturas com baixas relações água/cimento, de quatro superplastificantes comerciais de diferentes procedências a base de policarboxilatos, por meio de análise da base molecular, por meio do ensaio de teor de sólidos e por espectroscopia no infravermelho com transformada de Fourier (FTIR, do inglês Fourier-transform infrared spectroscopy), e da influência da sua utilização em pastas de cimento Portland, avaliando espalhamento, teor de ar incorporado, cinética de hidratação, resistência à compressão da mistura aos 28 dias e termogravimetria.

\section{MATERIAIS E MÉTODOS}

\subsection{Caracterização dos materiais}

O cimento Portland utilizado no presente estudo foi o CP V - ARI RS, equivalente ao cimento Tipo III especificado pela ASTM C150/C150M [15]. As principais características desse tipo de cimento são o elevado grau de finura e, no presente caso, a presença de $15 \%$ de material pozolânico (cinza volante) e $10 \%$ de fíler em sua composição. A composição química do cimento e as caracterizações física e mecânica deste material são apresentadas nas Tabelas 1e 2, respectivamente.

Tabela 1: Caracterização química do cimento Portland CP V - ARI RS.

\begin{tabular}{ll}
\hline CARACTERIZAÇÃO QUÍMICA & RESULTADOS (\%) \\
\hline Perda ao fogo & 5,4 \\
\hline $\mathrm{MgO}$ & 5,7 \\
\hline $\mathrm{SO} 3$ & 3,1 \\
\hline Resíduo insolúvel & 11,8
\end{tabular}

Fonte: Boletim de qualidade do fabricante - Boletim de Ensaios de Cimento (2019) 
Tabela 2: Caracterização física e mecânica do cimento Portland CP V - ARI RS.

\begin{tabular}{|c|c|}
\hline CARACTERIZAÇÃO FÍSICA & ${ }_{\text {DOS }}^{\text {RESULTA- }}$ \\
\hline Massa específica $\left(\mathrm{g} / \mathrm{cm}^{3}\right)$ & 2,97 \\
\hline Blaine $\left(\mathrm{cm}^{2} / \mathrm{g}\right)$ & 4800 \\
\hline Tempo de início de pega (min) & 220 \\
\hline Tempo de fim de pega (min) & 280 \\
\hline Finura peneira \#200 (\%) & 0,3 \\
\hline Expansibilidade (mm) & 0,0 \\
\hline $\begin{array}{l}\text { Resistência à compressão } 1 \text { dia } \\
(\mathrm{MPa})\end{array}$ & 20,3 \\
\hline $\begin{array}{l}\text { Resistência à compressão } 3 \text { dias } \\
(\mathrm{MPa})\end{array}$ & 30,2 \\
\hline $\begin{array}{l}\text { Resistência à compressão } 7 \text { dias } \\
(\mathrm{MPa})\end{array}$ & 35,5 \\
\hline $\begin{array}{l}\text { Resistência à compressão } 28 \text { dias } \\
(\mathrm{MPa})\end{array}$ & 47,4 \\
\hline
\end{tabular}

Fonte: Boletim de qualidade do fabricante - Boletim de Ensaios de Cimento (2019)

No presente estudo foram utilizados quatro aditivos comerciais à base de policarboxilatos de fornecedores distintos, sendo nomeados como A1, A2, A3 e A4. As caracterizações dos aditivos utilizados estão apresentadas na Tabela 3 .

Tabela 3: Caracterização dos aditivos fornecida pelos fabricantes.

\begin{tabular}{ccccc}
\hline ADITIVO & COMPOSIÇÃO & MASSA ESPECÍFICA $\left(\mathbf{g} / \mathbf{c m}^{\mathbf{3}}\right)$ & $\mathbf{p H}$ & DOSAGEM (\%) \\
\hline A1 & Policarboxilatos & $1,067-1,107$ & 5,80 a 7,80 & 0,2 a 1,2 \\
\hline A2 & Policarboxilato & $1,040-1,060$ & 3,00 a 5,50 & 0,4 a 1,2 \\
\hline A3 & Polímeros policarboxílicos & 1,120 & 6,15 & 0,2 a 5,0 \\
\hline A4 & Éter policarboxílico & 1,100 a 1,150 & 5,00 a 7,00 & 0,2 a 1,0 \\
\hline
\end{tabular}

Fonte: Fichas de informação dos fabricantes (2019)

Para a caracterização dos quatro aditivos, primeiramente, determinou-se o teor de sólidos de acordo com a metodologia descrita na NBR 10908 [16]. O procedimento foi realizado em três amostras, e o teor de sólidos foi definido a partir da média do resultado entre os três valores.

Analisando os resultados para o teor de sólidos apresentados na Tabela 4, constata-se que os aditivos A1, A2 e A3 apresentaram valores de aproximadamente 30\%, enquanto que o aditivo A4 exibiu um teor de sólidos superior, correspondente ao valor de $42 \%$.

Tabela 4: Teor de sólidos dos aditivos.

\begin{tabular}{ccc}
\hline \multirow{2}{*}{ ADITIVO } & \multicolumn{2}{c}{ TEOR DE SÓLIDOS (\%) } \\
\cline { 2 - 3 } & MÉDIA & DESVIO PADRÃO \\
\hline A1 & 30,382 & 0,181 \\
\hline A2 & 30,173 & 0,093 \\
\hline A3 & 42,047 & 0,189 \\
\hline A4 & 30,384 & 0,187 \\
\hline
\end{tabular}


A caracterização dos aditivos também foi realizada por meio do ensaio de FTIR, o qual avaliou o espectro de absorção de infravermelho das amostras dos quatros aditivos a base de policarboxilato avaliados na pesquisa. $\mathrm{O}$ ensaio foi realizado nas amostras líquidas, em um equipamento Cary 600 Series FTIR Spectrometer, com uma faixa de análise de 650 a $4000 \mathrm{~cm}^{-1}$ e resolução de $2 \mathrm{~cm}^{-1}$. Por meio da análise dos resultados dos espectros obtidos pelo ensaio de FTIR, apresentados na Figura 1, constatou-se comportamento similar entre todos os aditivos, comprovando-se a ocorrência de grupos funcionais característicos dos superplastificantes a base de policarboxilato. Foram identificados intervalos espectrais característicos do grupo $-\mathrm{OH}$ (em torno de $3445 \mathrm{~cm}^{-1}$ ), da ligação C-H de grupos orgânicos alifáticos $\left(3200-2500 \mathrm{~cm}^{-1}\right.$ ), grupos carbonilas $\left(1900-1500 \mathrm{~cm}^{-1}\right)$ e grupos éteres $\left(1250-950 \mathrm{~cm}^{-1}\right)[1,5]$.

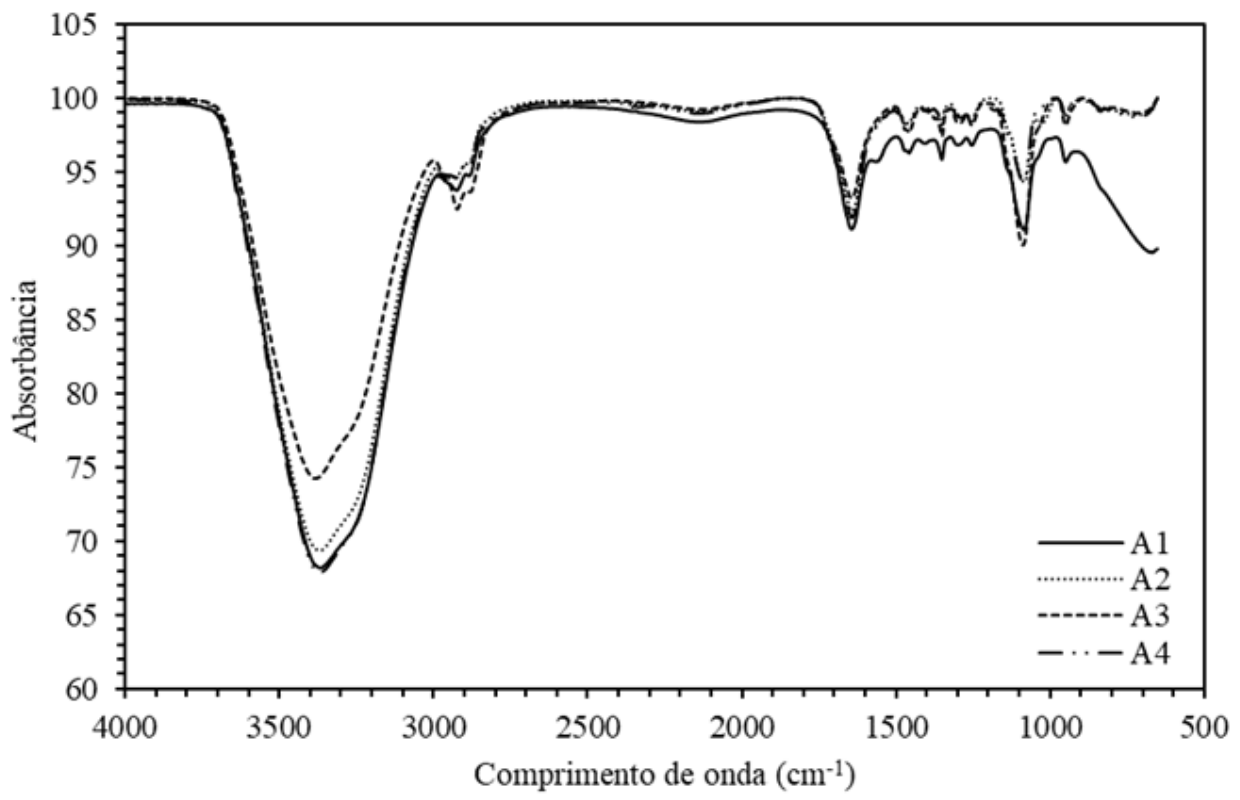

Figura 1: Espectro de infravermelho dos quatro aditivos à base de policarboxilatos avaliados na pesquisa

\subsection{Composições avaliadas}

O programa experimental foi realizado em pastas de cimento Portland, produzidas com duas relações água/cimento $(0,225$ e 0,300$)$ e aditivos comerciais de quatro fornecedores diferentes. Inicialmente, para a determinação das curvas que relacionaram o espalhamento com o teor de sólidos das misturas, foram produzidas pastas com teores de aditivos que variaram em função do teor de sólidos presente em cada aditivo e da relação água/cimento da pasta analisada. Para as misturas com relação água/cimento igual a 0,225, foram produzidas pastas com adições de aditivos variando de 0,15 a 1,8\% de teor de sólidos em relação a massa de cimento, para cada aditivo avaliado. Em relação as pastas com relação água/cimento de 0,300, os teores de sólidos de aditivos adicionados nas misturas variaram de 0,03 a $0,60 \%$ da massa de cimento. As variações nos teores foram definidas com base no comportamento de espalhamento das pastas, com o objetivo de gerar curvas com dados suficientes para a determinação do melhor teor a ser utilizado para cada relação água/cimento nos ensaios no estado fresco e nos ensaios de resistência à compressão, conforme apresentado no item 3.1 Espalhamento de pastas de cimento Portland. Além disso, esse intervalo de concentração também foi determinado levando em consideração como limite inferior teores que apresentassem alterações no espalhamento e, como limite superior, teores que não ocasionassem a exsudação das pastas. Com base nos resultados de teor de sólidos definidos no item supracitado, foram produzidas as pastas utilizadas nos ensaios no estado fresco e endurecido para cada relação água/cimento. Assim, para os ensaios de calorimetria, teor de ar incorporado, resistência à compressão axial e análise termogravimétrica foi produzida e avaliada apenas uma mistura para cada aditivo, por relação água/cimento.

Para todas as misturas estudadas no presente artigo, a produção foi realizada no misturador mecânico da marca Tedemix Ind. e Com. LTDA, modelo ML-03, cujo motor elétrico suporta uma rotação de 1760 RPM, possui potência de 0,75 HP, capacidade de até 2 litros, com haste tipo cawles de fluxo axial e 6,0 cm de diâmetro. Foi fixado um volume de material de $200 \mathrm{ml}$ e um tempo de mistura que variou de acordo com a rela- 
ção água/cimento (Tabela 5), levando em consideração que quanto menor a relação água/cimento da pasta, maior o tempo necessário para a ação do aditivo.

Tabela 5: Tempo de mistura de acordo com a relação água/cimento das pastas.

\begin{tabular}{cc}
\hline RELAÇÃO ÁGUA/CIMENTO & TEMPO DE MISTURA (MIN) \\
\hline 0,225 & 5 \\
\hline 0,300 & 2 \\
\hline
\end{tabular}

A determinação dos tempos de mistura foi realizada com base em testes de alteração na consistência das pastas por efeito do aditivo. Incialmente, as pastas foram produzidas com tempo correspondente a 2 minutos, no entanto, apenas as misturas com relação água/cimento equivalente a 0,300 apresentaram mudança na consistência dentro deste espaço de tempo. Dessa forma, para as misturas com relação água/cimento de 0,225 foram realizados testes com aumentos gradativos de tempo de mistura até as pastas apresentarem alteração na consistência por feito do aditivo. Estas alterações foram notadas nos testes realizados com tempo de mistura igual a 5 minutos, sendo, portanto, este o tempo de mistura estipulado para as pastas com relação água/cimento de 0,225 .

\subsection{Desempenho do aditivo frente ao espalhamento}

O desempenho dos aditivos avaliados frente ao espalhamento, foi realizado para pastas de diferentes relações água/cimento, por meio do ensaio de mini-abatimento, por meio da análise da curva que relaciona o espalhamento e o teor de sólidos utilizado.

O ensaio de mini-abatimento teve como objetivo a determinação da consistência de pastas de cimento Portland com a incorporação de aditivos superplastificantes. Desta forma, para a realização do ensaio foi utilizado um molde tronco-cônico em acrílico, de $60 \mathrm{~mm}$ de altura, $20 \mathrm{~mm}$ de diâmetro na parte superior e 40 $\mathrm{mm}$ de diâmetro na parte inferior, e uma placa de vidro. Depois de produzida, a pasta de cimento fresca foi imediatamente despejada no tronco-cônico sobre a placa, e este foi suspenso, permitindo o espalhamento da mistura. Foram registrados diâmetros de espalhamento ortogonais da pasta de cimento com o auxílio de um paquímetro digital. A temperatura ambiente, durante todo o teste, foi mantida em $23 \pm 0{ }^{\circ} \mathrm{C}$.

As misturas das pastas foram feitas de acordo com os procedimentos citados em 2.2 Composições Avaliadas.

\subsubsection{Determinação do teor de aditivos para ensaios no estado fresco e endurecido}

Analisando as curvas que relacionam o espalhamento e o teor de sólidos, constatou-se teores que apresentaram comportamento semelhante para as misturas em cada relação água/cimento. A partir desta análise, foram definidos, para cada relação água/cimento, os teores de sólido de aditivos utilizados nas misturas ensaiadas nos estados fresco e endurecido, considerando que o comportamento dos aditivos varia em função da relação água/cimento.

\subsection{Ensaios no estado fresco}

\subsubsection{Calorimetria de condução isotérmica}

De acordo com SCRIVENER, SNELLIGNS e LOTHENBACH [18] a calorimetria isotérmica é ideal para quantificar a influência de aditivos na taxa de hidratação do cimento, além de possibilitar a identificação da existência de incompatibilidades entre o ligante e o aditivo. Isto posto, a cinética do processo de hidratação do cimento Portland foi avaliada por calorimetria de condução isotérmica, em um calorímetro Thermometric AB da TAM Air da TA Instruments. A liberação de calor foi registrada durante 72 horas, a uma temperatura de $23{ }^{\circ} \mathrm{C} \pm 0{ }^{\circ} \mathrm{C}$. As pastas foram preparadas de acordo com o procedimento descrito em 2.2 Composições Avaliadas.

\subsubsection{Teor de ar incorporado}

O conhecimento do teor de ar incorporado em uma mistura cimentícia é de suma importância, uma vez que esse tem influência direta na sua trabalhabilidade e nas propriedades mecânicas [17, 18]. Os valores dos teores de ar incorporado foram obtidos por meio de correlação entre as massas específicas aferidas e as massas especificas teóricas sem vazios das respectivas misturas cimentícias, seguindo o procedimento descrito na 
NBR 13278 [21].

\subsection{Resistência à compressão axial}

Foram produzidos corpos de prova cilíndricos de pastas de cimento com dimensões de $20 \mathrm{~mm}$ de diâmetro e $40 \mathrm{~mm}$ de altura. $\mathrm{O}$ adensamento foi realizado manualmente e os corpos de prova foram submetidos à cura imersa, em água, por 28 dias. Após os 28 dias de cura, os corpos de prova foram retificados em uma cortadeira metalográfica, da marca Bluehler, com um disco de corte diamantado. Esses foram ensaiados à compressão axial em uma prensa universal da marca Instron, modelo 5569, com uma taxa de carregamento de 0,50 $\mathrm{MPa} / \mathrm{s}$. Com os resultados obtidos para cada mistura, foram realizadas análises estatísticas de variância (ANOVA), a fim de verificar se existem diferenças estatisticamente significativas entre os valores médios de resistência à compressão.

\subsection{Análise termogravimétrica}

A análise termogravimétrica das pastas de cimento aos 28 dias de idade foi realizada no equipamento SDT Q600 da TA Instruments. As amostras foram aquecidas até uma temperatura de aproximadamente $1000{ }^{\circ} \mathrm{C}$, com uma taxa de aquecimento de $20{ }^{\circ} \mathrm{C} / \mathrm{min}$ e um fluxo de $\mathrm{N}_{2}$ de $100 \mathrm{ml} / \mathrm{min}$. Inicialmente, as pastas de cimento foram mantidas no nitrogênio líquido para interromper as reações de hidratação do cimento Portland e, posteriormente, foram moídas manualmente em um almofariz de ágata, e o material utilizado na análise foi o passante na peneira de malha quadrada de $0,075 \mathrm{~mm}$ de abertura.

$\mathrm{O}$ teor de hidróxido de cálcio $\left(\mathrm{Ca}(\mathrm{OH})_{2}\right)$ foi calculado de acordo com a Equação 1, considerando que a decomposição deste composto geralmente ocorre na faixa de temperatura de $400-500{ }^{\circ} \mathrm{C}$ [18].

$\mathrm{Ca}(\mathrm{OH})_{2}=\mathrm{WL} \mathrm{Ca}(\mathrm{OH})_{2} \cdot \mathrm{m} \mathrm{Ca}(\mathrm{OH})_{2} / \mathrm{m} \mathrm{H}_{2} \mathrm{O}$

Onde:

WL $\mathrm{Ca}(\mathrm{OH})_{2}$ - perda de massa do hidróxido de cálcio;

$\mathrm{m} \mathrm{Ca}(\mathrm{OH})_{2}$ - massa molar do hidróxido de cálcio $(74 \mathrm{~g} / \mathrm{mol})$;

$\mathrm{m}_{2} \mathrm{O}$ - massa molar da água $(18 \mathrm{~g} / \mathrm{mol})$.

\section{RESULTADOS E DISCUSSÕES}

\subsection{Espalhamento de pastas de cimento Portland}

Resultados reológicos do comportamento de pastas de cimento com baixa relação água/cimento são estudados no artigo de LIU et al. [12]. Segundo os autores, a influência de superplastificantes na dosagem de pastas de cimento com baixa relação água/cimento tem sido amplamente pesquisada. LIU et al. [12] ainda indicam que para relações água/cimento equivalentes a $0,32,0,24$ e 0,20 , os efeitos no espalhamento das pastas de cimento obedecem uma tendência de crescimento. Ainda, os autores afirmam que em pastas de cimento com alta relação água/cimento, o efeito do superplastificante é mais perceptível. Para obter determinado espalhamento, é necessária uma maior quantidade de superplastificante em pastas de cimento com baixa relação água/cimento.

As Figuras 2 e 3 apresentam os resultados de espalhamento para as pastas de cimento Portland produzidas com relação água/cimento de 0,225 e 0,300 , respectivamente, em função do teor de sólidos dos quatro aditivos comerciais à base de policarboxilatos analisados neste estudo. 


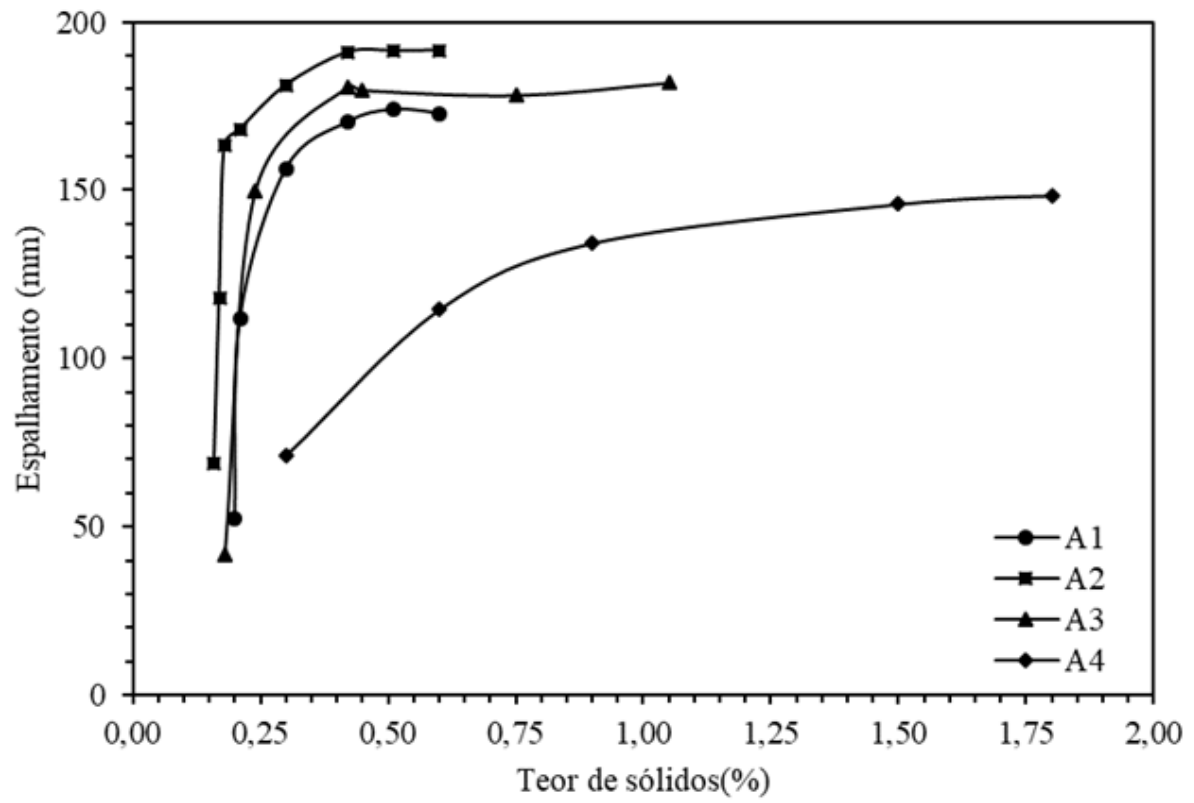

Figura 2: Espalhamento das pastas com relação água/cimento $=0,225$.

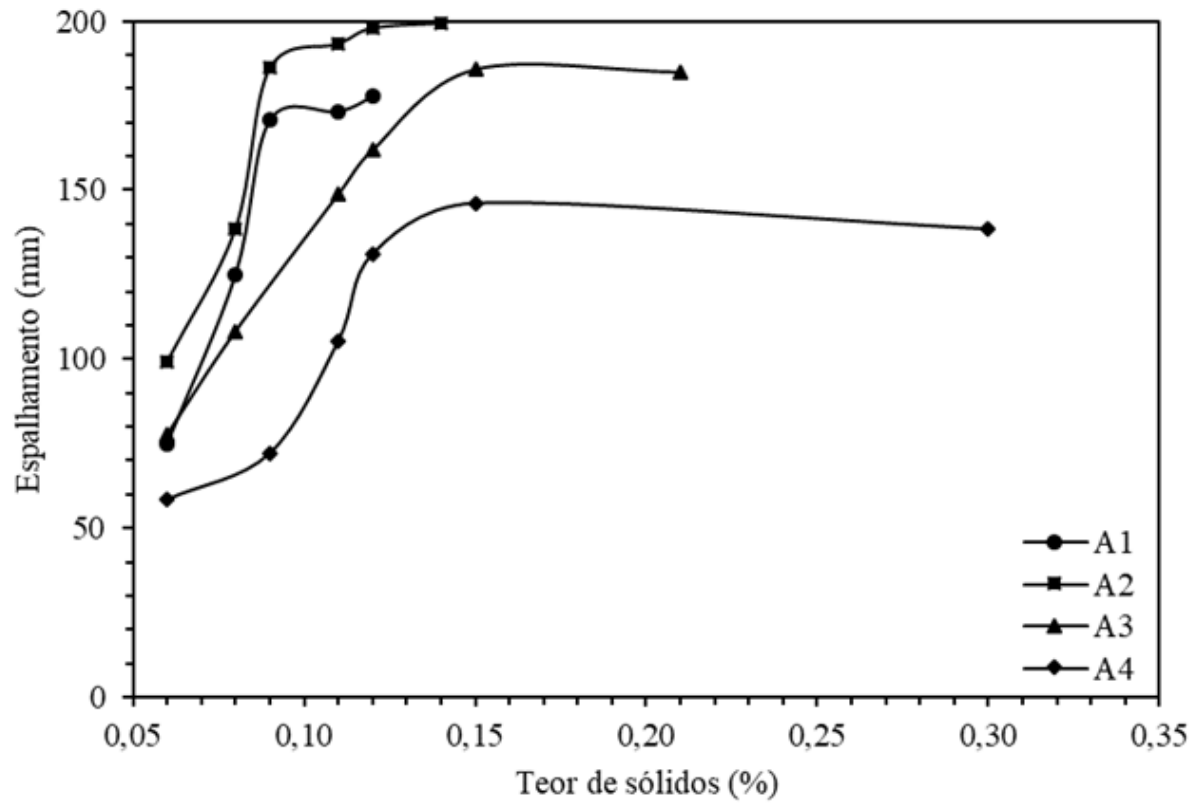

Figura 3: Espalhamento das pastas com relação água/cimento $=0,300$.

Avaliando as curvas de espalhamento em função do teor de sólidos apresentadas para cada aditivo, ilustradas nas Figuras 2 e 3, identificou-se um desempenho semelhante entre os aditivos A1, A2 e A3, em comparação com o aditivo A4, que apresentou desempenho, consideravelmente, inferior aos demais. O comportamento dos aditivos A1, A2 e A3 foi considerado equivalente, uma vez que as curvas de espalhamento apresentaram desenvolvimento similar, com valores próximos entre si, quando comparado com o aditivo A4. Ainda, o patamar do valor de espalhamento dos aditivos A1, A2 e A3 foi atingido a partir da adição do mesmo teor de sólidos. Outro ponto análogo entre os três aditivos são os valores de espalhamento máximo aproximados, os quais são significativamente superiores aos do aditivo A4.

Os aditivos A1, A2 e A3 proporcionaram às misturas cimentícias comportamento mais sensível do seu espalhamento em função do aumento do teor de sólidos, visto que mesmo pequenas variações do teor de sóli- 
dos conduziram a um aumento pronunciado do espalhamento. O aditivo A4, em função de dispor uma curva de inclinação mais suave, necessita de maior variação do teor de sólidos para apresentar o mesmo espalhamento que os demais aditivos. Quando avaliados os espalhamentos proporcionados pelos aditivos na relação água/cimento de 0,300, tem-se uma maior desigualdade nos resultados obtidos para um mesmo teor de sólidos, quando comparados com as demais relações água/cimento, apesar de apresentarem a mesma tendência da relação 0,225 .

Após análise dos gráficos de espalhamento por teor de sólidos e avaliação da qualidade das misturas produzidas quanto ao espalhamento e exsudação, foram definidos os teores de sólidos utilizados na produção das pastas submetidas aos ensaios no estado fresco e endurecido para cada relação água/cimento. A determinação dos teores foi baseada em valores que abrangessem espalhamentos estudados e demonstrados nas Figuras 2 e 3 para todos os aditivos, considerando, ainda, a qualidade desse espalhamento. Dessa forma, foram definidos teores que garantissem, simultaneamente, o máximo espalhamento para os quatro aditivos analisados, evitando a ocorrência de exsudação. Na Tabela 6 estão apresentados os teores de sólidos definidos para cada relação água/cimento em função do objetivo do presente trabalho.

Tabela 6: Teores utilizados nos ensaios no estado fresco e endurecido.

\begin{tabular}{cc}
\hline RELAÇÃO ÁGUA/CIMENTO & TEOR DE SÓLIDOS UTILIZADO (\%) \\
\hline 0,225 & 0,50 \\
\hline 0,300 & 0,12 \\
\hline
\end{tabular}

Comparando o teor definido na Tabela 6 para a relação água/cimento 0,225 com as curvas da Figura 2, percebe-se que o teor de sólidos de $0,50 \%$ apresenta alteração no espalhamento dos quatro aditivos analisados. Para os aditivos A1, A2 e A3, o teor se enquadra no patamar de constância do espalhamento sem exsudação, enquanto que para o aditivo A4 o teor definido está na ascensão da curva do espalhamento, sendo visível a alteração na consistência da pasta por efeito do aditivo. O teor de sólidos definido para a relação 0,300 , equivalente a $0,12 \%$, apresentou alterações no espalhamento de todos os aditivos, com comportamentos semelhantes nas curvas da Figura 3, ou seja, próximo ao patamar de escoamento do traço, sem exsudar.

\subsection{Calorimetria isotérmica}

O período inicial de hidratação começa durante a mistura do cimento com a água e é caracterizado por vários processos exotérmicos, promovendo a hidratação das partículas de cimento e a consequente formação de etringita, aluminatos e sulfatos de cálcio. Após o período inicial ocorre o período de indução, que é caracterizado pela dissolução e deposição dos compostos hidratados do cimento, formando uma barreira de produtos em torno das partículas de cimento, ocasionando a inibição momentânea da hidratação das partículas de cimento, o qual pode ser caracterizado por um período de baixa liberação de calor. Com o passar do tempo, a barreira formada na superfície das partículas de cimento é superada e as partículas voltam a ser hidratadas. Este comportamento pode ser observado em um gráfico padrão de calorimetria onde ocorre uma ascensão abrupta, isso é caracterizado pela elevada liberação de calor. A desaceleração do fluxo de calor advém da hidratação da alita [22-24].

Para a relação água/cimento 0,225, verifica-se na Figura 4, que nas pastas produzidas com os aditivos A2, A3 e A4 há um deslocamento do segundo pico de calor para tempos maiores, em relação à curva calorimétrica da pasta produzida com o aditivo A1. Segundo ZING et al. [25], esse comportamento pode estar associado à maior massa molecular dos aditivos A2, A3 e A4 em relação ao aditivo A1, sendo que maiores densidades carboxílicas e menores cadeias laterais inferem no aumento do período de indução. De acordo com HE et al. [17], maiores densidades carboxílicas melhoram a quantidade de adsorção das moléculas, isso porque, maior adsorção dificulta a difusão de íons, fazendo com que ocorra um aumento no período de indução. Os autores corroboram o comportamento descrito anteriormente, por meio da análise termogravimétrica das pastas de cimento, a qual evidenciou um aumento do período de indução nas pastas com a adição de aditivo à base de policarboxilato. Os resultados de termogravimetria indicam um retardo no processo de hidratação das partículas de cimento das pastas com aditivo plastificante, uma vez que foi verificada que a formação de portlandita e C-S-H, produtos da hidratação do cimento Portland, ocorre após 4 horas na pasta de referência, (sem aditivo plastificante), e, apenas após 18 horas na pasta com aditivo.

Nas Figuras 4 e 5 observa-se que, por mais que ocorra um aumento do período de indução, diminuindo o calor liberado acumulado nas primeiras horas, o calor acumulado total é o mesmo para todas as misturas com os diferentes aditivos. $\mathrm{O}$ aumento do período de dormência da pasta produzida com o aditivo A3 em 
relação ao A2 para a relação água/cimento 0,225 sugere a hipótese do aditivo A3 ter maior massa molecular e/ou menor cadeia lateral e/ou menor quantidade de cadeia lateral. Já para os demais aditivos, se pode inferir que o aditivo A1 tem menor massa molecular e/ou maior tamanho de cadeia e/ou maior quantidade de cadeias laterais [26].

O comportamento de prolongamento da reação de hidratação também está ligado a diferentes capacidades de adsorção do polímero na superfície do clínquer, quanto maior essa adsorção maior é o prolongamento da indução [26, 27]. A capacidade de adsorção da molécula está ligada ao comprimento da cadeia lateral, e esta é beneficiada pela diminuição do tamanho da cadeia [28]. Assim, pode ser verificado que há uma tendência do aditivo A3 ter a maior capacidade de adsorção e consequentemente menor tamanho de cadeia lateral em relação aos demais aditivos, já que seu período de dormência é mais prolongado, conforme ilustrado nas Figuras 4 e 5.

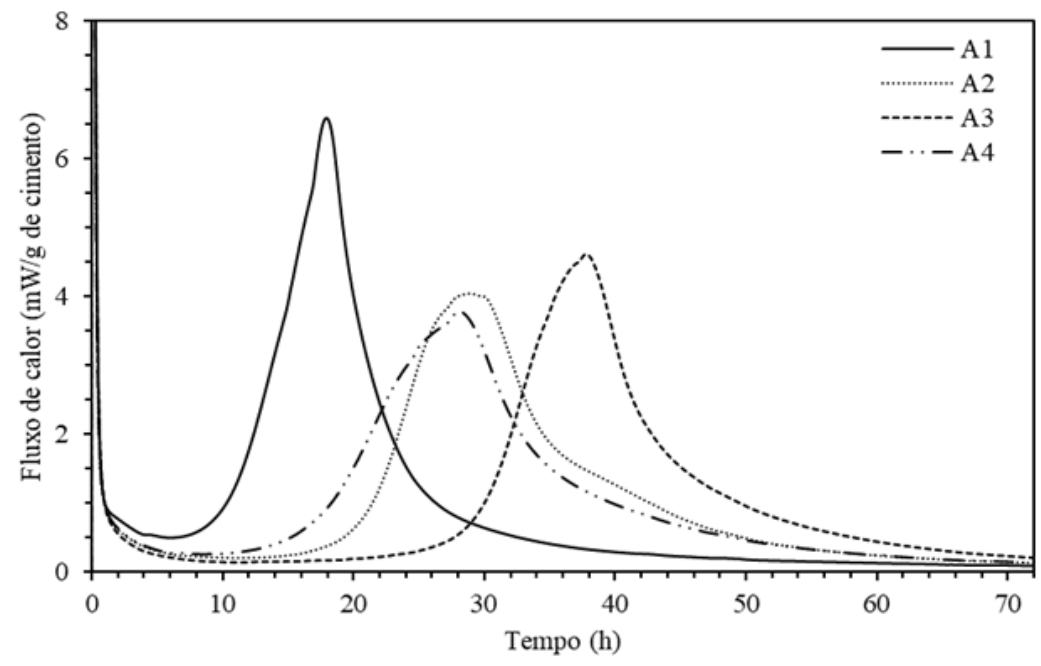

Figura 4: Fluxo de calor das pastas com relação água/cimento $=0,225$.

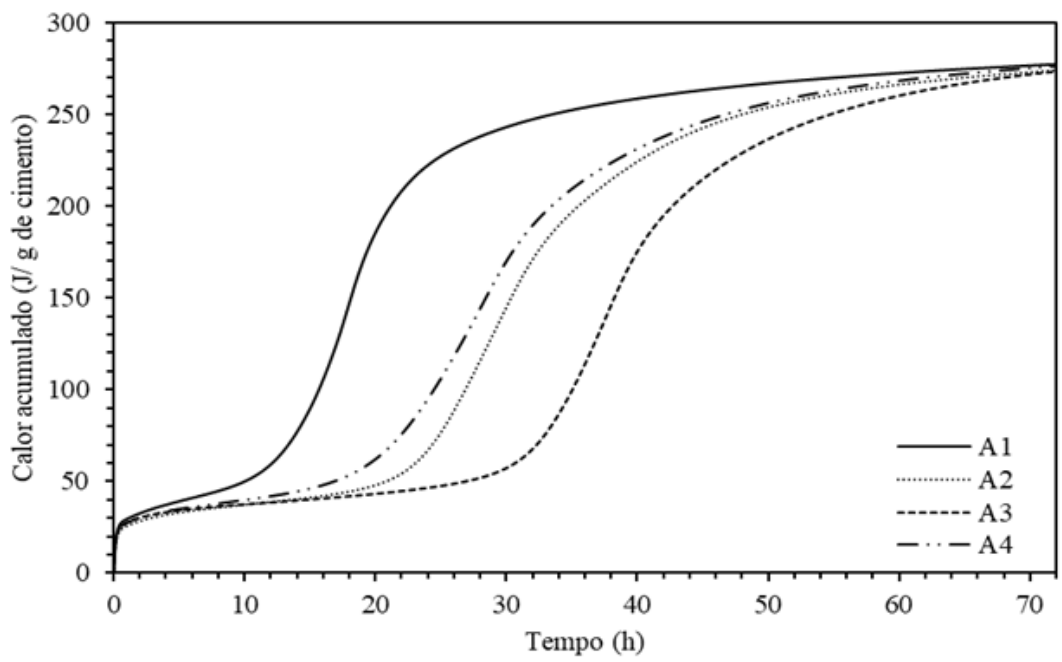

Figura 5: Calor acumulado das pastas com relação água/cimento $=0,225$.

Pode ser verificado nas Figuras 6 e 7, que o aditivo A1 encurtou o período de indução da pasta com relação água/cimento 0,300, o que também foi evidenciado na relação água/ligante 0,225. Bem como, o aditivo A3 mostrou um maior período de indução para todas as matrizes cimentícias produzidas no presente estudo. Assim, conforme supracitado, infere-se que A3 tem maior massa molecular e/ou menor cadeia lateral e/ou menor quantidade de cadeia lateral e que A1 tem menor massa molecular e/ou maior tamanho de cadeia e/ou maior quantidade de cadeias laterais. 
Como já relatado anteriormente, quanto maior a adsorção do polímero no clínquer maior é o seu período de indução $[24,25]$. Assim, pode ser verificado que há uma tendência do aditivo A3 ter a maior capacidade de adsorção em relação aos demais aditivos, já que seu período de dormência é mais prolongado, conforme ilustrado nas Figuras 6 e 7. Bem como, infere-se que A3 tem uma maior massa molecular e menor cadeia lateral ocasionando maiores períodos de indução.

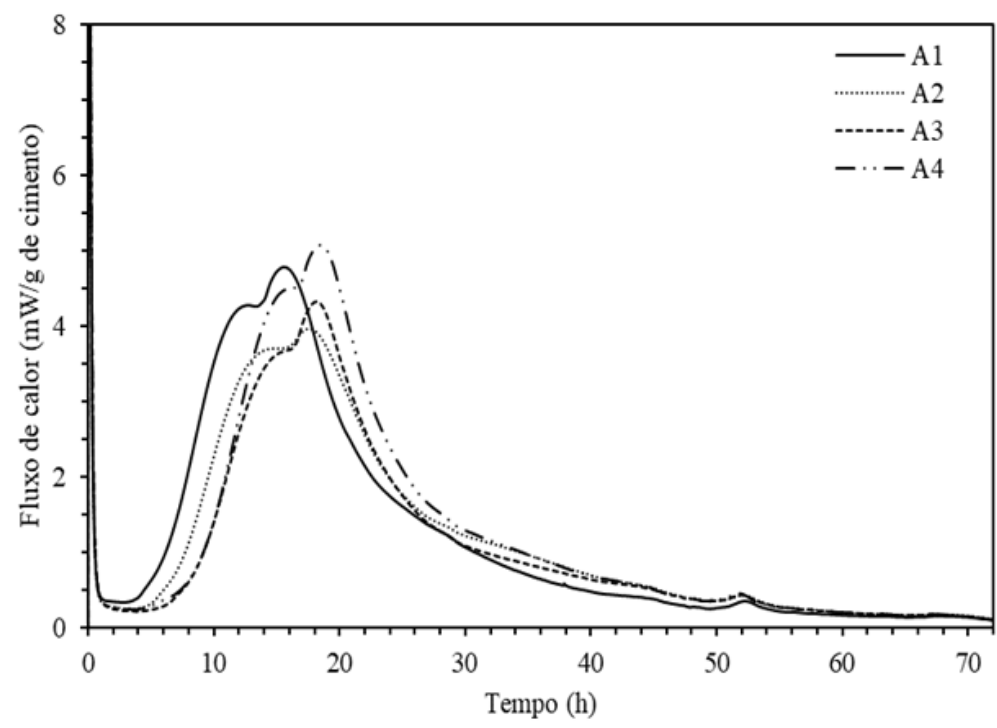

Figura 6: Fluxo de calor das pastas com relação água/cimento $=0,300$.

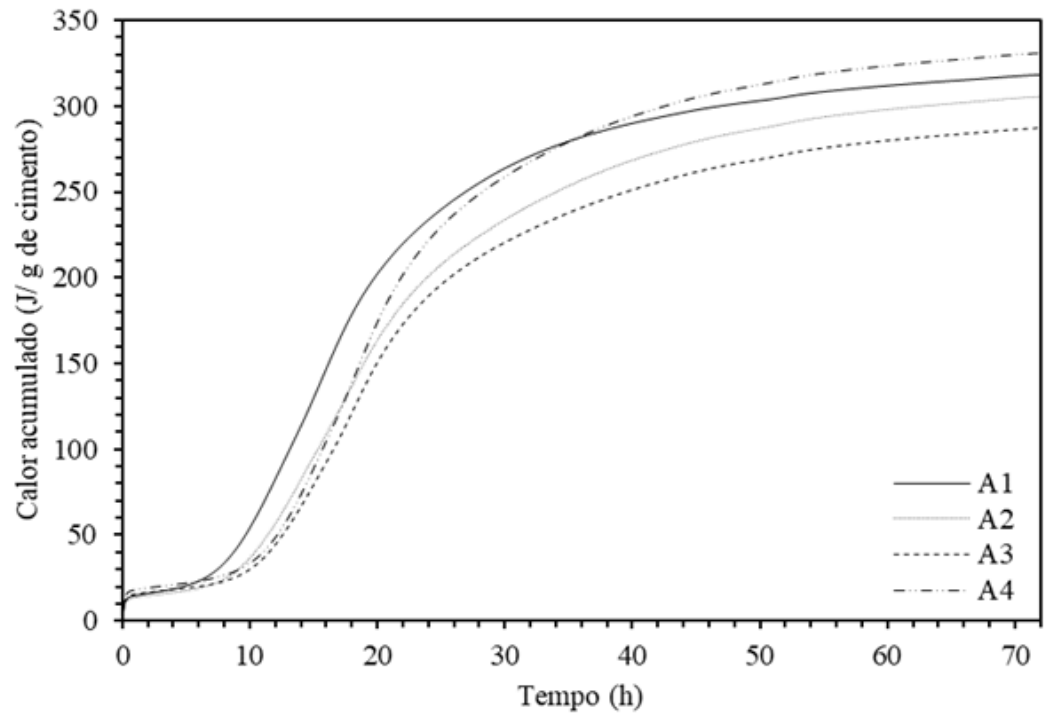

Figura 7: Calor acumulado das pastas com relação água/cimento $=0,300$.

A fim de complementar a análise dos dados de calorimetria, determinou-se o período de indução das pastas de cimento avaliadas na pesquisa, seguindo o procedimento empregado por BETIOLI [29]. Na Tabela 7 são apresentados os resultados encontrados. 
Tabela 7: Estimativa do período de indução das pastas de cimento com os aditivos A1, A2, A3 e A4 e relações água/cimento de 0,225 e 0,3000

\begin{tabular}{ccccc}
\hline $\begin{array}{c}\text { RELAÇÃO } \\
\text { ÁGUA/CIMENTO }\end{array}$ & ADITIVO & INÍCIO (H) & FIM (H) & DURAÇÃO (H) \\
\hline \multirow{2}{*}{0,225} & A1 & 0,42 & 6,58 & 6,16 \\
\cline { 2 - 5 } & A2 & 0,34 & 18,97 & 18,63 \\
\cline { 2 - 5 } & A3 & 0,63 & 28,53 & 27,91 \\
\hline \multirow{2}{*}{0,300} & A4 & 0,48 & 15,36 & 14,88 \\
\hline & A1 & 0,41 & 5,18 & 4,78 \\
\hline & A2 & 0,43 & 5,92 & 5,49 \\
\hline & A3 & 0,48 & 6,98 & 6,50 \\
\hline & A4 & 0,42 & 4,83 & 4,41 \\
\hline
\end{tabular}

Verifica-se que o aditivo A3 foi o responsável pelos maiores períodos de indução para ambas as relações água/cimento avaliadas. Em relação às pastas de cimento com os menores períodos de indução para as relações água/cimento de 0,225 e 0,300 , o aditivo A3 promoveu um período de indução $35 \%$ e $48 \%$ superior, respectivamente. Dessa forma, constata-se que diferentes tipos de aditivos alteram a cinética de hidratação da mistura. Essa diferença no comportamento ocorre porque cada aditivo possui características diferentes de uma mesma molécula, diferenciando-se no seu tamanho da sua molécula, cadeias laterais, peso molecular e a adsorção da molécula nos compostos químicos do clínquer [2].

\subsection{Teor de ar incorporado}

Os aditivos superplastificantes, além de reduzirem a necessidade de água para uma mesma trabalhabilidade, tem influência sobre o teor de ar incorporado em uma mistura cimentícia [30]. Dessa maneira, a Figura 8 apresenta os resultados obtidos para o teor de ar incorporado de cada mistura avaliada.

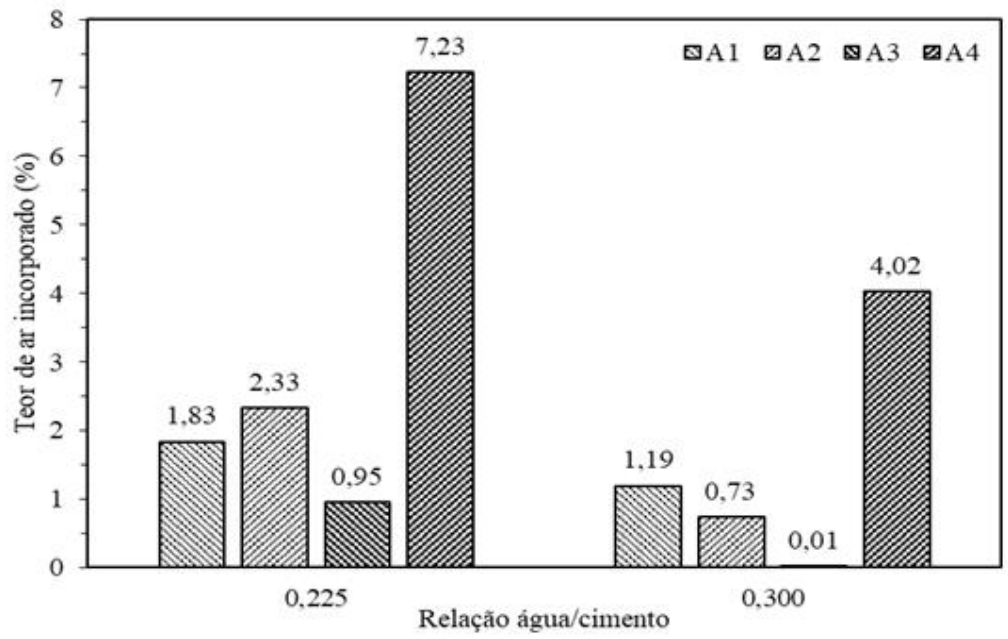

Figura 8: Teor de ar incorporado das pastas de cimento Portland.

Os dados expostos na Figura 8 permitem constatar que os aditivos A1, A2 e A3 mantêm resultados próximos quando comparados aos resultados apresentados pelo aditivo A4 em ambas as relações água/cimento analisadas, uma vez que a diferença do último aditivo para os demais é de no mínimo quatro vezes maior.

Ao verificar os teores de ar, apresentados na Figura 8, com os resultados do ensaio de espalhamento expostos nas Figuras 2 e 3, percebe-se que o aditivo A4 apresentou a maior incorporação de ar ao mesmo tempo 
em que apresentou o menor espalhamento para um mesmo teor de sólidos, tanto para a relação água/cimento de 0,225 quanto para a de 0,300. Segundo AÏTCIN [19] e ÖZCAN e KOÇ [20], a trabalhabilidade de misturas cimentícias está diretamente relacionada ao teor de ar incorporado, uma vez que para um mesmo traço, a mistura que apresenta maior quantidade de bolhas de ar no estado fresco promove maior espalhamento. De acordo com DILS, BOEL e SCHUTTER [31], verifica-se que o comportamento do aditivo A4 é distinto dos demais superplastificantes e do relatado na literatura, se mostrando menos viável que os demais, uma vez que contém maior incorporação de ar em misturas de relação água/cimento menores.

\subsection{Resistência à compressão axial}

O ensaio de resistência à compressão foi realizado aos 28 dias após a data de produção das pastas para todas as relações água/cimento estudadas e todos os aditivos empregados. Os resultados obtidos estão dispostos na Figura 9. Para a apresentação dos dados, consideram-se as médias aritméticas para cada relação água/cimento e o desvio padrão correspondente.

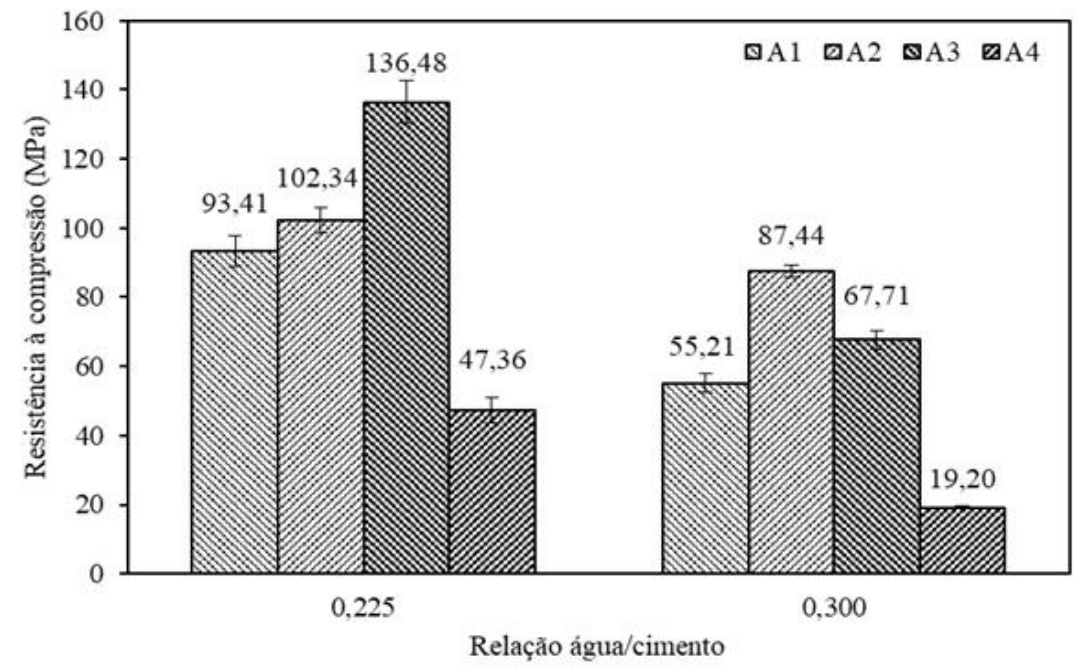

Figura 9: Resistência à compressão uniaxial das pastas aos 28 dias.

Para as pastas de relação água/cimento 0,225 os resultados do ensaio de resistência à compressão indicaram que a inserção do aditivo A3 contribuiu de forma mais significativa quando comparado aos demais aditivos. Este aditivo resultou em um aumento de resistência à compressão de $33 \%$ em relação à $\mathrm{A} 2$, cerca de $46 \%$ à $\mathrm{A} 1$ e $188 \%$ à A4. Além disso, verifica-se que A1 e A2 resultaram em resistências próximas, porém estatisticamente diferentes, sendo que A2 aprimorou a resistência à compressão cerca de $9 \%$ em relação à A1 e $116 \%$ à A4. Infere-se ainda que, as pastas com aditivo A1 obtiveram uma resistência $97 \%$ maior que com A4.

Já para as pastas de relação água/cimento 0,300 os resultados do ensaio indicaram que entre os quatro aditivos utilizados no presente estudo, o aditivo A2 foi o que contribuiu de forma mais significativa, alcançando maiores valores de resistência à compressão. Seus valores foram cerca de $29 \%$ maior que A3, 58\% em relação à A1 e 355\% maior do que A4. Observa-se também que, A3 obteve valores de resistência à compressão maiores que A1 e A4 por volta de $22 \%$ e $252 \%$, respectivamente. Já o aditivo A1 indicou um resultado $187 \%$ maior que A4.

Para as relações água/cimento estudadas, as pastas com aditivos A2 e A3, resultaram nos maiores valores de resistência à compressão aos 28 dias. Já as pastas com os aditivos A1 e A4, indicaram os menores valores. Isso pode ser relacionado com os valores de ar incorporado pelas misturas, bem como, as características físicas e químicas das moléculas dos aditivos. Aditivos que possuem moléculas que tem por características prolongamento do período de indução, como é o caso dos aditivos A2 e A3, podem fazer com que a estrutura da matriz cresça com maior homogeneidade garantindo assim resultados maiores de resistência à compressão. Quanto maior for o teor de ar incorporado por uma mistura maior será a redução de suas propriedades mecânicas [30]. A maior incorporação de ar para ambas as relações água/cimento foi encontrada nas matrizes produzidas com o aditivo A4 o que resultou em menores resistências à compressão.

Além disso, com o intuito de verificar a influência dos fatores controláveis: relação água/cimento (A) e 
tipo de aditivo (B), bem como a interação entre tais fatores (AB), aplicou-se ao conjunto de dados de resistência à compressão uma análise de variância (ANOVA). Na Tabela 8, são apresentados os resultados encontrados nessa análise. Considerando um nível de confiabilidade de 95\%, constatou-se que a relação água/cimento e o tipo de aditivo, assim como a interação entre esses fatores, exercem influência significativa na resistência à compressão.

Tabela 8: Análise de variância (ANOVA) dos resultados de resistência à compressão.

\begin{tabular}{ccccccc}
\hline FONTE & SQ & GDL & MQ & TESTE F & PROBABILIDADE & INFLUÊNCIA \\
\hline A & 7217,163 & 1 & 7217,163 & 609,223 & $0,000000000000067 \%$ & $\mathrm{~S}$ \\
\hline $\mathrm{B}$ & 16780,459 & 3 & 5593,486 & 472,163 & $0,000000000000001 \%$ & $\mathrm{~S}$ \\
\hline $\mathrm{AB}$ & 4302,778 & 3 & 1434,259 & 121,070 & $0,000000000145938 \%$ & $\mathrm{~S}$ \\
\hline Erro & 225,084 & 19 & 11,847 & & \\
\hline Total & 28525,485 & $* \mathrm{~S}-$ Significativa &
\end{tabular}

Posteriormente, foi realizada a comparação de médias entre os diferentes tipos de aditivos para as relações água/cimento de 0,225 e 0,300. Assim, verifica-se com 95\% de confiabilidade que todos os traços apresentaram diferenças estatisticamente significativas em relação à resistência à compressão média. Afirma-se assim que, diferentes tipos de aditivos resultam em diferentes resistências à compressão para uma mesma relação água/cimento.

\subsection{Análise Termogravimétrica}

As Figuras 10 e 11 apresentam os resultados da análise termogravimétrica e termogravimetria derivada das pastas de cimento Portland compostas pelos aditivos superplastificantes A1, A2, A3 e A4 com relações água/cimento de 0,225 e 0,300, respectivamente. Já na Tabela 9 constam as perdas de massa associadas às curvas termogravimétricas para alguns intervalos de temperatura pré-estabelecidos. De acordo com ALMEIDA E SCHIERI [32] e SCRIVNER, SNELLINGS E LOTHENBACH [18], no ensaio de termogravimetria a perda de massa entre $20-105^{\circ} \mathrm{C}$ pode ser associada à água livre presente nos poros das pastas de cimento, entre $105-400{ }^{\circ} \mathrm{C}$ à formação dos silicatos de cálcio hidratados, entre $400-500{ }^{\circ} \mathrm{C}$ ao hidróxido de cálcio e, por fim, entre $600-800{ }^{\circ} \mathrm{C}$ ao carbonato de cálcio.

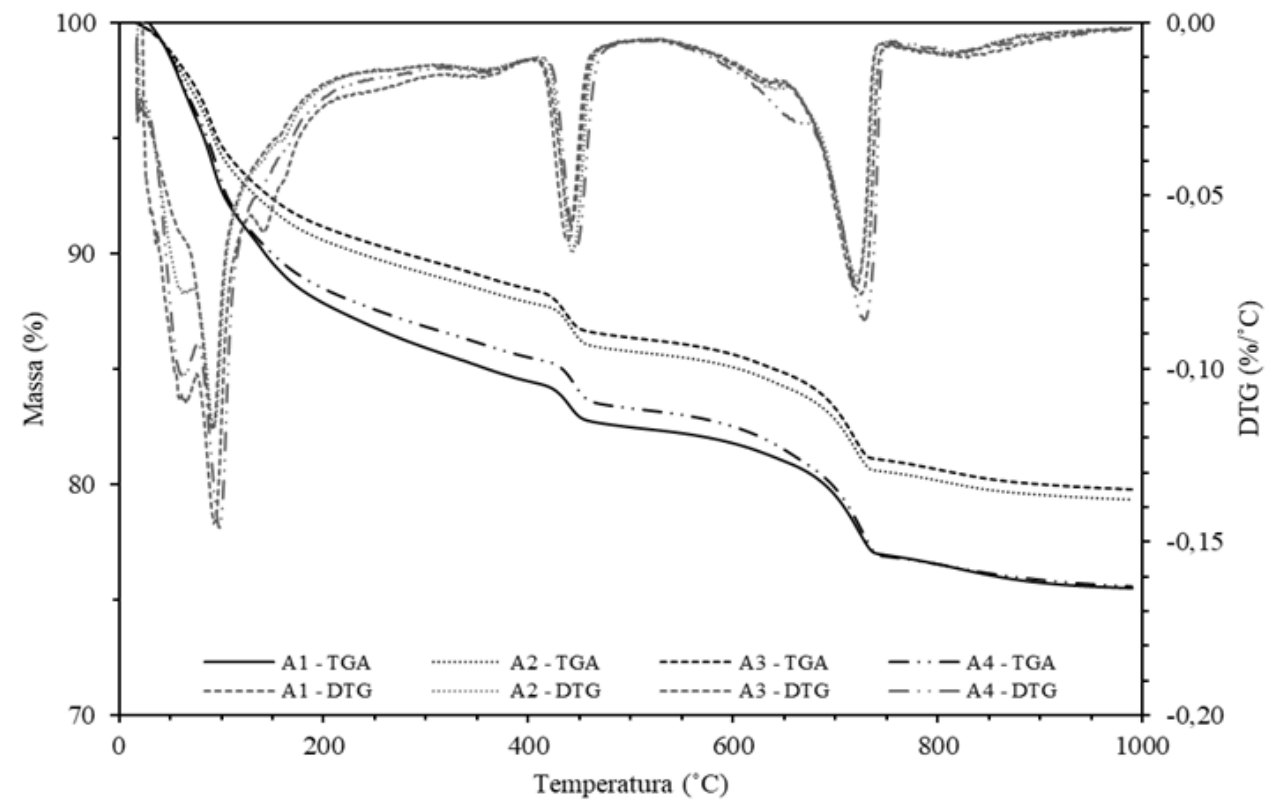

Figura 10: Análise termogravimétrica (TGA) e termogravimetria derivada (DTG) das pastas com os aditivos A1, A2, A3 e A4 e relação água/cimento $=0,225$ aos 28 dias. 


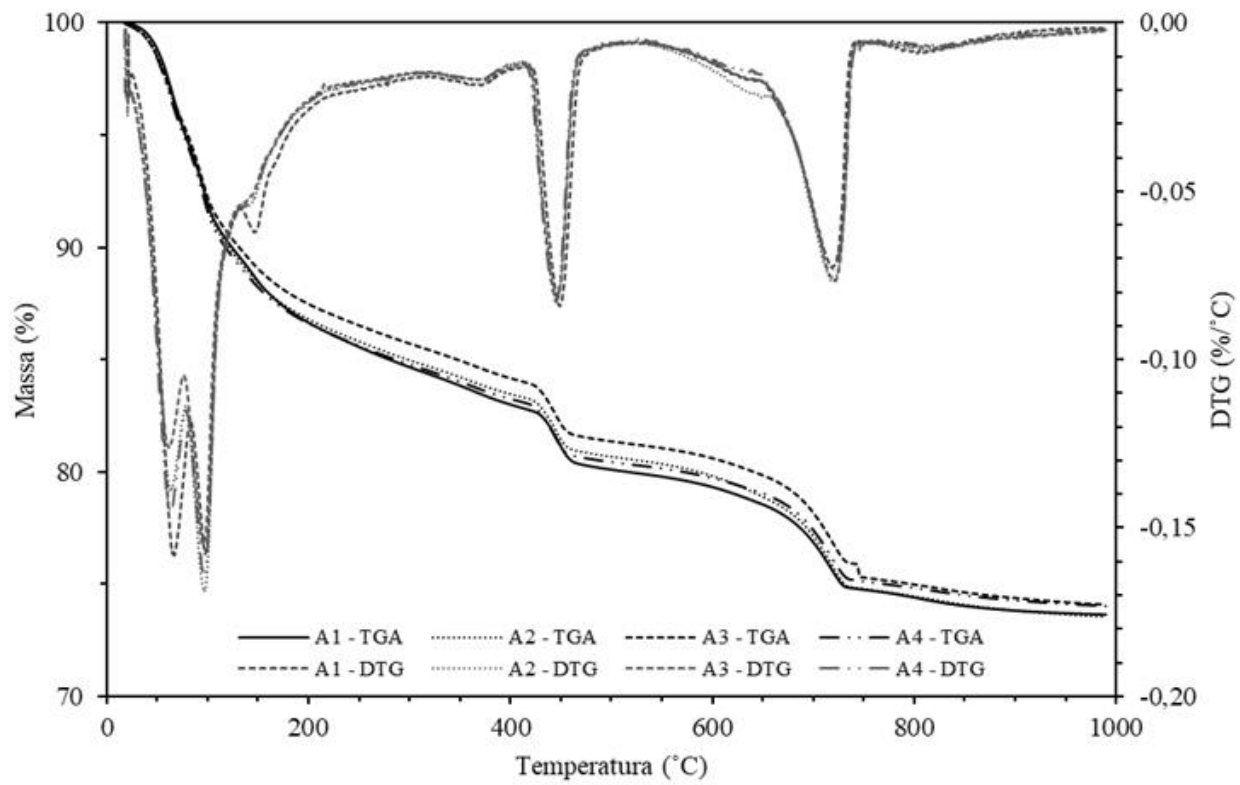

Figura 11: Análise termogravimétrica (TGA) e termogravimetria derivada (DTG) das pastas com os aditivos A1, A2, A3 e A4 e relação água/cimento $=0,300$ aos 28 dias.

Tabela 9: Perdas de massa (\%) associadas às curvas termogravimétricas.

\begin{tabular}{ccccccccc}
\hline \multirow{2}{*}{$\begin{array}{c}\text { FAIXA DE TEMPERA- } \\
\text { TURA }\end{array}$} & \multicolumn{3}{c}{ RELAÇÃO A/C = 0,225 } & \multicolumn{4}{c}{ RELAÇÃO A/C = 0,300 } \\
\cline { 2 - 9 } & A1 & A2 & A3 & A4 & A1 & A2 & A3 & A4 \\
\hline $20-105^{\circ} \mathrm{C}$ & 7,75 & 6,09 & 5,65 & 7,49 & 8,65 & 8,83 & 8,30 & 9,03 \\
\hline $105-400^{\circ} \mathrm{C}$ & 7,83 & 6,03 & 5,90 & 7,01 & 8,35 & 10,50 & 7,53 & 7,72 \\
\hline $400-500^{\circ} \mathrm{C}$ & 2,00 & 2,13 & 2,11 & 2,21 & 2,90 & 2,79 & 2,81 & 2,81 \\
\hline $600-800^{\circ} \mathrm{C}$ & 5,2 & 4,91 & 4,98 & 5,96 & 4,92 & 5,37 & 5,63 & 4,90 \\
\hline
\end{tabular}

Isto posto, é possível observar a partir dos resultados expressos na Tabela 9 que, de maneira geral, para ambas as relações água/cimento avaliadas na pesquisa, as pastas compostas pelos aditivos A2 e A3 apresentaram uma porcentagem de água livre inferior às pastas com os aditivos A1 e A4. Correlacionado esse comportamento com os resultados de resistência à compressão axial obtidos, levanta-se a hipótese de que quanto menor a quantidade de água livre nos poros das pastas, menor a porosidade da matriz e, consequentemente, maior a resistência à compressão. Contudo, tal tendência não se mantém quando a faixa de temperatura de $105-400{ }^{\circ} \mathrm{C}$ é analisada, uma vez que não se obteve uma relação entre as pastas com maiores resistências à compressão e maiores percentuais de perda de massa associados à formação do C-S-H, principal composto responsável pelo desempenho mecânico de matrizes cimentícias. Destaca-se apenas o caso da pasta com relação água/cimento de 0,300 composta pelo aditivo A2, a qual apresentou maior resistência à compressão em relação às demais pastas, bem como um percentual de perda de massa expressivamente superior associado à formação de C-S-H. Diante do exposto, acredita-se que os teores de ar incorporado pelos aditivos tiveram maior impacto nos valores de resistência à compressão em comparação com possíveis modificações na microestrutura das pastas de cimento em função das diferentes características das moléculas de policarboxilato.

Nesse sentido, os percentuais de perda de massa associados à faixa de temperatura de 400 a $500{ }^{\circ} \mathrm{C}$ podem ser utilizados no cálculo do teor de hidróxido de cálcio das amostras, conforme previamente apresentado na Equação 1. Desta forma, verificou-se um percentual de hidróxido de cálcio de 8,20\%, 8,76\%, 8,66\% e 9,09\% para as pastas moldadas com relação água/cimento de 0,225 e aditivos A1, A2, A3 e A4, respectivamente. Já para as pastas com relação água/cimento de 0,300, estes valores foram de 11, 93\%, 11,47\%, $11,57 \%$ e $11,56 \%$. De acordo com MOUNANGA et al. [33], o grau de hidratação do cimento pode ser linearmente associado ao teor de hidróxido de cálcio. Desta forma, verifica-se que todas as pastas de cimento da pesquisa apresentaram percentuais de hidróxido de cálcio semelhantes, o que indica um grau de hidratação equivalente. Esse comportamento é esperado, visto que as pastas foram moldadas com as mesmas relações 
água/cimento, apresentando como única diferença o tipo de aditivo em sua composição. Nesse contexto, HE et al. [17] constataram por meio da análise termogravimétrica que com a evolução do tempo, diferentes densidades de policarboxilatos tem pouca influência na quantidade de C-S-H e hidróxido de cálcio formados.

Por fim, a perda de massa no intervalo de $600-800^{\circ} \mathrm{C}$ pode ser relacionada com a decomposição do carbonato de cálcio presente no cimento [18], que no caso do CP V - ARI RS, pode ter um teor de substituição de cimento Portland por material carbonático de até 10\%, conforme especificado na NBR 16697 [34]. Desta forma, os teores de carbonato de cálcio quantificados nas pastas são compostos pela parcela oriunda do material carbonático que compõe o cimento e, eventualmente, por uma parcela referente à carbonatação indesejada das amostras.

\section{CONCLUSÕES}

- Os resultados mostraram que cada aditivo possui uma característica diferente de uma mesma molécula, diferenciando-se no tamanho da sua molécula, cadeias laterais, peso molecular e a adsorção da molécula nos compostos químicos do clínquer, e assim, acarretando diferentes propriedades no estado fresco, endurecido e microestruturais para uma mesma mistura cimentícia.

- Aditivos de mesma base molecular não necessariamente terão comportamentos semelhantes. Ressaltando a importância de serem realizados testes prévios entre o aditivo e a mistura cimentícia que será produzida para verificar o seu desempenho e sua interação com o tipo de cimento utilizado.

- Conforme foi evidenciado nos ensaios, há uma tendência de um aditivo com maior densidade molecular, e/ou menor quantidade e/ou tamanho de cadeias laterais, resultar em menores teores de ar incorporado em matrizes cimentícias e com isso acarreta maior resistência á compressão. Com isso, pode ocorrer uma melhora na qualidade da matriz, bem como, aprimorar a durabilidade de uma mistura cimentícia.

\section{REFERÊNCIAS}

[1] JANOWSKA-RENKAS, E., "The influence of the chemical structure of polycarboxylic superplasticizers on their effectiveness in cement pastes", Procedia Engineering, v. 108, p. 575-583, 2015.

[2] RAMACHANDRAN, V. S., MALHOTRA, V. M., JOLICOEUR, C., SPIRATOS, N., "Superplasticizers: Properties and applications in concrete", CANMET: Ottawa, 1998.

[3] LAZNIEWSKA-LIEKARCZYK, B., "Influence of temperature on the properties of non-air-entrained cement mortars modified with diferente plasticisers and superplasticisers types", MATEC Web conferences, 2018.

[4] MEHTA, K. P., MONTEIRO, M. J. P., "Concreto: microestrutura, propriedades e materiais", 2a edição, Edição: Nicole Pagan Rasparyk, IBRACON: São Paulo, 2014.

[5] BATRAKOV, Modified concrete: Theory and practice, 1998.

[6] VALENTINI, L., DALCONI, M. C., ARTIOLI, G., "Role of polycarboxylate-ether superplasticizers on cement hydration kinetics and microstructural development", MATEC Web conferences, 2018.

[7] RIXOM, M.R., MAILVAGANAM, N.P., "Chemical admixtures for concrete", Taylor \& Francis eLibrary, 2002.

[8] MONTE, R., FIGUEIREDO, A. D., "Avaliação de métodos de ensaio de fluidez em pastas de cimento com aditivos superplastificantes", Boletim Técnico, Escola Politécnica da Universidade de São Paulo, Departamento de Engenharia de Construção Civil, São Paulo, 2013.

[9] GOLASZEWSKI, J., "Influence of cement properties on new generation superplasticizers performance", Construction and Building Materials, v. 35, p. 586-596, 2012.

[10] LANGE, A, HIRATA, T., PLANK, J., "Influence of HLB value of polycarboxylate superplasticizers on the flow behavior of mortar and concrete", Cement and Concrete Research, v. 60, p. 45-50, 2014.

[11] RAN, Q., SOMASUNDARAM, P., MIAO, C., LIU, J., WU, S., SHEN, J., "Effect of the length of the side chains of comb-like copolymer dispersants on dispersion and rheological properties of concentrated cement suspensions", Journal of colloid and interface science, v. 336, n. 2, p. 624-633, 2009.

[12] LIU, J., WANG, K., ZHANG, Q., HAN, F., SHA, J., LIU, J. "Influence of superplasticizer dosage on the viscosity of cement paste with low water-binder ratio", Construction and Building Materials, v. 149, p. 359366. 2017. 
[13] TIAN, H., KONG, X., SU, T, WANG, D., "Comparative study of two PCE superplasticizers with varied charge density in Portland cement and sulfoaluminate cement systems," Cement and Concrete Research, v. 115 , p. 43-58, 2019.

[14] ZHANG, Y., CAI, X., KONG X., GAO, L., "Effects of comb-shaped superplasticizers with different charge characteristics on the microstructure and properties of fresh cement pastes," Construction and Building Materials, v. 155, p. 441-450, 2017.

[15] AMERICAN SOCIETY FOR TESTING AND MATERIALS, "ASTM C150/C150M: Standard Specification for Portland Cement", 2018.

[16] ASSOCIAÇÃO BRASILEIRA DE NORMAS TÉCNICAS, "NBR 10908: Aditivos para argamassa e concreto - Ensaios de Caracterização", Rio de Janeiro, 2008.

[17] HE, Y., ZHANG, X., SHUI, L., WANG, Y., GU, M., WANG, X., WANG, H., PENG, L., "Effects of PCEs with various carboxylic densities and functional groups on the fluidity and hydration performances of cement pastes", Construction and Building Materials, v. 202, p. 656-668, 2019.

[18] SCRIVENER, K., SNELLINGS, R., LOTHENBACH, B., "A practical guide to microstructural analysis of cementitious materials", Taylor \& Francis Group, 2016.

[19] AÏTCIN, P.C., "Entrained air in concrete: Rheology and freezing resistance, In: Science and Technology of Concrete Admixtures", Woodhead Publishing, 2016. p. 87-95.

[20] ÖZCAN, F., KOÇ, M. E., "Influence of ground pumice on compressive strength and air content of both non-air and air entrained concrete in fresh and hardened state", Construction and Building Materials, v. 187, p. 382-393, 2018.

[21] ASSOCIAÇÃO BRASILEIRA DE NORMAS TÉCNICAS, "NBR 13278: Argamassa para assentamento e revestimento de paredes e tetos - Determinação da densidade de massa e do teor de ar incorporado", Rio de Janeiro, 2005.

[22] KORPA, A., KOWALD, T., TRETTIN, R., "Phase development in normal and ultra-high performance cementitious systems by quantitative X-ray analysis and thermoanalytical methods", Cement Concrete Research, p. 69-76, 2009.

[23] PFEIFER C., MÖSER B., STARK J., "Hydration, phase and microstructure development of ultra-high performance concrete", ZKG International, v. 63, p. 71-79. 2009.

[24] HESSE, C., GOETZ-NEUNHOEFFER, F., NEUBAUER, J., "A new approach in quantitative in-situ XRD of cement pastes: correlation of heat flow curves with early hydration reactions", Cement Concrete Research, p. 123-128, 2011.

[25] ZING, A., WINNEFELD, F., HOLZER, L., PAKUSCH, J., BECKER, S., FIGI, R., GAUCKLER, L. "Interaction of polycarboxylate-based superplasticizers with cements containing different C3A amounts", Cement and Concrete Composites, 31(3), p. 153-162. 2009.

[26] KONG, F. R., PAN, L. S., WANG, C. M., XU, N., "Effects of polycarboxylate superplasticizers with different molecular structure on the hydration behavior of cement paste", Construction and building materials, p. 545-553, 2016

[27] JANSEN, D., NEUBAUER, J., GOETZ-NEUNHOEFFER, F., HAERZSCHEL, R., HERGETH, W. D, "Change in reaction kinetics of a Portland cement caused by a superplasticizer - Calculation of heat flow curves from XRD data", Cement and Concrete Research, p. 327-332, 2012.

[28] XIAO-DONG, W. LEI, F. DONG-YUAN, H. KAI, W. ZHANG, Z., "Effect of side-chain length in polycarboxylic superplasticizer on the early-age performance of cement-based materials", Construction and Building Materials, p. 26-32, 2019.

[29] BETIOLI, Andrea Murillo. "Influência dos polímeros MHEC e EVA na hidratação e comportamento reológico de pastas de cimento Portland", Tese (Doutorado em Engenharia Civil) - Programa de PósGraduação em Engenharia Civil, Universidade Federal de Santa Catarina, Florianópolis, 2007.

[30] BÜYÜKYAĞCI, A., TUZCU, G., ARAS, L., "Synthesis of copolymers of methoxy polyethylene glycol acrylate and 2-acrylamido-2-methyl-1-propanesulfonic acid: Its characterization and application as superplasticizer in concrete", Cement and Concrete Research, v. 39, n. 7, p. 629-635, 2009.

[31] DILS, J., BOEL, V., SCHUTTER, G., "Influence of cement type and mixing pressure on air content, rheology and mechanical properties of UHPC", Construction and Building Materials, v. 41, p. 455-463, 
2013..

[32] ALMEIDA, A. E. F. S., SICHIERI, E. P., "Thermogravimetric analyses and mineralogical study of polymer modified mortar with silica fume", Materials Research, v. 9, n. 3, p. 321-326, 2006.

[33] MOUNANGA, P., KHELIDJ, A., LOUKILI, A., BAROGHEL-BOUNY, V., "Predicting Ca(OH)2 content and chemical shrinkage of hydrating cement pastes using analytical approach", Cement and Concrete Research, v. 34, p. 255-265, 2004.

[34] ASSOCIAÇÃO BRASILEIRA DE NORMAS TÉCNICAS, "NBR 16697: Cimento Portland-Requisitos", Rio de Janeiro, 2018.

\section{ORCID}

André Valmir Saugo Ribero

Laura Silvestro

Ana Julia Zunta Carniel

Matheus Agustini

Priscila Warsch

Wellington Longuini Repette

Philippe Jean Paul Gleize http://orcid.org/0000-0003-1156-0938

http://orcid.org/0000-0002-6437-3047

http://orcid.org/0000-0002-5756-3598

http://orcid.org/0000-0001-6533-8369

http://orcid.org/0000-0003-0592-3069

http://orcid.org/0000-0003-0697-2794

https://orcid.org/0000-0003-4029-9345 